05,11

\title{
Магнитоуправляемые термоупругие мартенситные превращения и свойства мелкозернистого сплава $\mathrm{Ni}_{54} \mathrm{Mn}_{21} \mathrm{Ga}_{25}$
}

\author{
(C) В.Г. Пушин ${ }^{1,2}$, Е.Б. Марченкова ${ }^{1}$, А.В. Королев ${ }^{1,2}$, Н.И. Коуров ${ }^{1}$, \\ Е.С. Белослудцева ${ }^{1}$, А.В. Пушин ${ }^{1}$, А.Н. Уксусников ${ }^{1}$ \\ ${ }^{1}$ Институт фризики металлов им. М.Н. Михеева УрО РАН, \\ Екатеринбург, Россия \\ ${ }^{2}$ Уральский фредеральный университет им. Б.Н. Ельцина, \\ Екатеринбург, Россия \\ E-mail: pushin@imp.uran.ru
}

(Поступила в Редакцию 25 октября 2016 г.)

В интервале температур $2-400 \mathrm{~K}$ проведены сравнительные исследования физических характеристик (электросопротивления, магнитной восприимчивости, намагниченности, деформации на изгиб и степени восстановления формы при последующем нагреве) литого и быстрозакаленного из расплава ферромагнитного сплава $\mathrm{Ni}_{54} \mathrm{Mn}_{21} \mathrm{Ga}_{25}$. Полученные данные сопоставлены с результатами изучения структурнофазовых превращений, выполненных методами просвечивающей и сканирующей электронной микроскопии и рентгенодифрактометрии. Установлено влияние быстрой закалки на микроструктуру, магнитное состояние, критические температуры и особенности термоупругих мартенситных превращений в сплаве. Обнаружено рекордное повышение ресурса его пластичности и термомеханической циклостойкости при изгибе в межкритическом интервале температур и последующем нагреве.

Работа выполнена при поддержке Российского научного фонда (грант № 15-12-10014).

Использовалось аналитическое оборудование ЦКП „Испытательный центр нанотехнологий и перспективных материалов“ ИФМ УрО РАН.

DOI: 10.21883/FTT.2017.07.44591.396

\section{1. Введение}

Сплавы на основе интерметаллических соединений NiTi $\left(\mathrm{Ni}_{50} \mathrm{Ti}_{50}\right)$ и $\mathrm{Ni}_{2} \mathrm{MnGa}\left(\mathrm{Ni}_{50} \mathrm{Mn}_{25} \mathrm{Ga}_{25}\right.$, содержание компонентов приведено в аt.\%) вызывают неослабевающий интерес исследователей благодаря многообразию структурных и фазовых превращений при охлаждении, нагреве и под нагрузкой и, как следствие, их большому инновационному потенциалу [1-4]. Как и во многих сплавах с термоупругими мартенситными превращениями (ТМП) в сплавах этих систем фазовым превращениям предшествует ярко выраженное предпереходное размягчение модулей упругости и смягчение ряда фононных мод [1-8]. Существенным следствием ТМП в них является наличие эффектов памяти формы (ЭПФ), которые в ферромагнетиках типа $\mathrm{Ni}_{2} \mathrm{MnGa}$ могут контролироваться внешним магнитным полем [4] в отличие от других сплавов, например на основе никелида титана [1-3].

$L 2_{1}$-сплавы Гейслера на основе $\mathrm{Ni}_{50} \mathrm{Mn}_{25} \mathrm{Ga}_{25}$ при охлаждении и под нагрузкой испытывают последовательные структурные превращения мартенситного типа в фазы с более низкой чем $L 2_{1}$ симметрией [9]. Мартенситные фазы могут различаться по типу структуры и имеют не только тетрагональную, но и длиннопериодную, орторомбическую или моноклинно-искаженную решетку [10-12]. При этом разными дифракционными методами регистрируются основные наиболее интенсивные структурные отражения и более слабые экстра- рефлексы. Интерпретация экстрарефлексов, практически эквидистантно расположенных вдоль определенных направлений обратной решетки, допускает их неоднозначное описание: они могут интерпретироваться как проявление формирования субструктуры, модулированной периодическими сдвигами по системе (110) [1ㅣㅣ в решетке $L 2_{1}$ или как результат появления новых практически соизмеримых фаз с длиннопериодной, почти пятикратной или семикратной укладкой исходных плотноупакованных плоскостей (110) $L 2_{1}$. Такой мартенсит обозначается как пятислойный типа $(3 \overline{2})$, или $5 M$, или семислойный типа $(5 \overline{2})$, или $7 M[10-12]$. При другом выборе описания типа кристаллической решетки указанные мартенситные фазы обозначаются как $10 M$ и $14 M$ соответственно.

При ТМП под механической нагрузкой возможно образование еще одной фазы - объемно центрированной тетрагональной (ОЦТ) мартенситной фазы, степень тетрагональности которой $c / a \sim 1.2$, а направление оси $c$ при деформации монокристалла $\mathrm{Ni}_{50} \mathrm{Mn}_{25} \mathrm{Ga}_{25}$ устанавливается вдоль оси растяжения или перпендикулярно оси сжатия [13]. Такая же немодулированная ОЦТ-фаза (NM), тетрагональность которой варьируется в зависимости от химического состава в пределах $c / a \sim 1.18-1.23$, может возникать при охлаждении в нестехиометрических сплавах [12].

Из данных структурной нейтронографии [9] известно, что аустенитная высокотемпературная фаза 
в стехиометрическом интерметаллическом соединении $\mathrm{Ni}_{50} \mathrm{Mn}_{25} \mathrm{Ga}_{25}$ - прототипе исследуемого в настоящей работе сплава - имеет атомно-упорядоченную кристаллическую сверхструктуру $L 2_{1}$ (типа Гейслера). Структура нестехиометрических сплавов на основе данного соединения изучена менее подробно и в основном методами рентгенографии и дифракции электронов. Вследствие близости атомных факторов рассеяния химических элементов, входящих в сплавы, остаются не вполне выясненными тип и степень атомного упорядочения сплавов в высокотемпературном состоянии и их влияние на ТМП и ЭПФ $[4,9,14]$. Недостаточно изучена реальная структура данных сплавов и в случае использования методов синтеза и внешних воздействий, приводящих к существенно неравновесным состояниям $[4,13,14]$.

Среди ферромагнитных сплавов на основе $\mathrm{Ni}_{50} \mathrm{Mn}_{25} \mathrm{Ga}_{25}$, обладающих магнитоуправляемыми ЭПФ, нестехиометрический сплав $\mathrm{Ni}_{54} \mathrm{Mn}_{21} \mathrm{Ga}_{25}$ занимает особое место [15-20]. Его температуры начала и конца прямого $\left(M_{s}, M_{f}\right)$ и обратного $\left(A_{s}, A_{f}\right)$ ТМП, определяющие ЭПФ, и температура Кюри $T_{C}$ близки к комнатной, и это удобно как при выполнении исследований, так и в случае возможного практического использования. В свою очередь интерес к технологии сверхбыстрой закалки из расплава (БЗР) обусловлен прежде всего стремлением к созданию более пластичных ультрамелкозернистых состояний в сплавах, так как катастрофическим недостатком обычных литых крупнозернистых сплавов данной системы является их чрезвычайная хрупкость [21]. Поэтому в настоящей работе выполнены сравнительные исследования структуры и физических свойств литого ферромагнитного сплава состава $\mathrm{Ni}_{54} \mathrm{Mn}_{21} \mathrm{Ga}_{25}$, полученного в исходном атомно-упорядоченном состоянии с типом решетки $L 2_{1}$, и БЗР-сплава того же химического состава.

\section{2. Материалы и методика исследований}

Сплав номинального состава $\mathrm{Ni}_{54} \mathrm{Mn}_{21} \mathrm{Ga}_{25}$ (в at.\%) был изготовлен методом дуговой плавки в инертной среде на водоохлаждаемом медном поду. Исходными компонентами служили высокочистые металлы (чистотой 99.99\%). Слитки сплава подвергались длительному гомогенизирующему отжигу, а затем из них электроискровым методом вырезались образцы в виде пластин для измерений физических свойств и структурно-фазовых исследований.

Сверхбыстрое охлаждение выполнялось в инертной среде методом спиннингования струи расплава на быстро вращающемся медном барабане со скоростью охлаждения $10^{5} \mathrm{~K} / \mathrm{s}$, в результате чего были получены образцы в виде тонких (толщиной $40 \mu \mathrm{m}$ ) и достаточно пластичных лент (химический состав приведен в табл. 1) в отличие от хрупких образцов исходного литого сплава того же интегрального химического состава.
Таблица 1. Химический состав исследуемого БЗР-сплава $\mathrm{Ni}_{54} \mathrm{Mn}_{21} \mathrm{Ga}_{25}$

\begin{tabular}{c|c|c}
\hline \multirow{2}{*}{ Элемент } & \multicolumn{2}{|c}{ Содержание } \\
\cline { 2 - 3 } & wt.\% & at.\% \\
\hline $\mathrm{Mn}$ & 18.89 & 20.87 \\
$\mathrm{Ni}$ & 52.21 & 53.97 \\
$\mathrm{Ga}$ & 28.90 & 25.16
\end{tabular}

Сплавы изучались в исходном литом состоянии, после БЗР и отжига. Измерялись электрическое сопротивление по схеме двойного моста, магнитная восприимчивость и намагниченность в широком интервале температур $(2-400 \mathrm{~K})$ на вибромагнитометре VSM (LAKE SHORE) и СКВИД-магнитометре MPMS-5XL (Quantum Design), деформация образцов при изгибе и степень восстановления их формы за счет ЭПФ при нагреве.

Электронно-микроскопические исследования проводились на трансмиссионных электронных микроскопах (TEM) JEM-200CX (JEOL), Tecnai G ${ }^{2} 30$ и CM 30 (FEI), a также на сканирующем электронном микроскопе (SEM) Quanta-200 Pegasus (FEI), оборудованном системами энергодисперсионного анализа и анализа методом дифракции обратно рассеянных электронов. Рентгеновский анализ выполняся на дифрактометре ДРОН-3М в монохроматизированном $\mathrm{Cu} K_{\alpha}$-излучении.

\section{3. Электросопротивление сплавов}

При температурах выше комнатной ( $T$ больше $A_{f}$ и $T_{C}$ ) величина удельного электросопротивления в исследованном сплаве $\rho$ составляла более $120 \mu \Omega \cdot \mathrm{cm}$ и слабо зависела от его микроструктурного состояния (литого или после БЗР). В парамагнитном состоянии $\rho(T)$ определяется в основном фононной и магнитной составляющими, которые практически не зависят от способа получения данных сплавов в условиях достаточно близких значений их точек Кюри и температур Дебая, a также величины эффективного момента $\mu_{\text {eff }}[22,23]$. Напротив, в области низких температур ( $T$ много меньше $M_{f}$ и $T_{C}$ ) величина сопротивления обусловлена прежде всего рассеянием электронов проводимости на неоднородностях кулоновского потенциала в кристалле, т.е. определяется степенью атомного порядка и дефектностью структуры. Поэтому остаточное сопротивление $\rho_{0}$ образца исходного атомно-упорядоченного сплава $\mathrm{Ni}_{54} \mathrm{Mn}_{21} \mathrm{Ga}_{25}$ значительно (примерно в 4 раза) меньше, чем $\rho_{0}$ быстрозакаленного и, очевидно, частично разупорядоченного сплава того же химического состава.

Из рис. $1, a, b$ и 2 видно, что в зависимости от способа синтеза сплавов поведение $\rho(T)$, как и $\chi(T)$, сильно изменялось и в окрестности температур ТМП. Для БЗР-сплава в достаточно узком интервале темпе- 

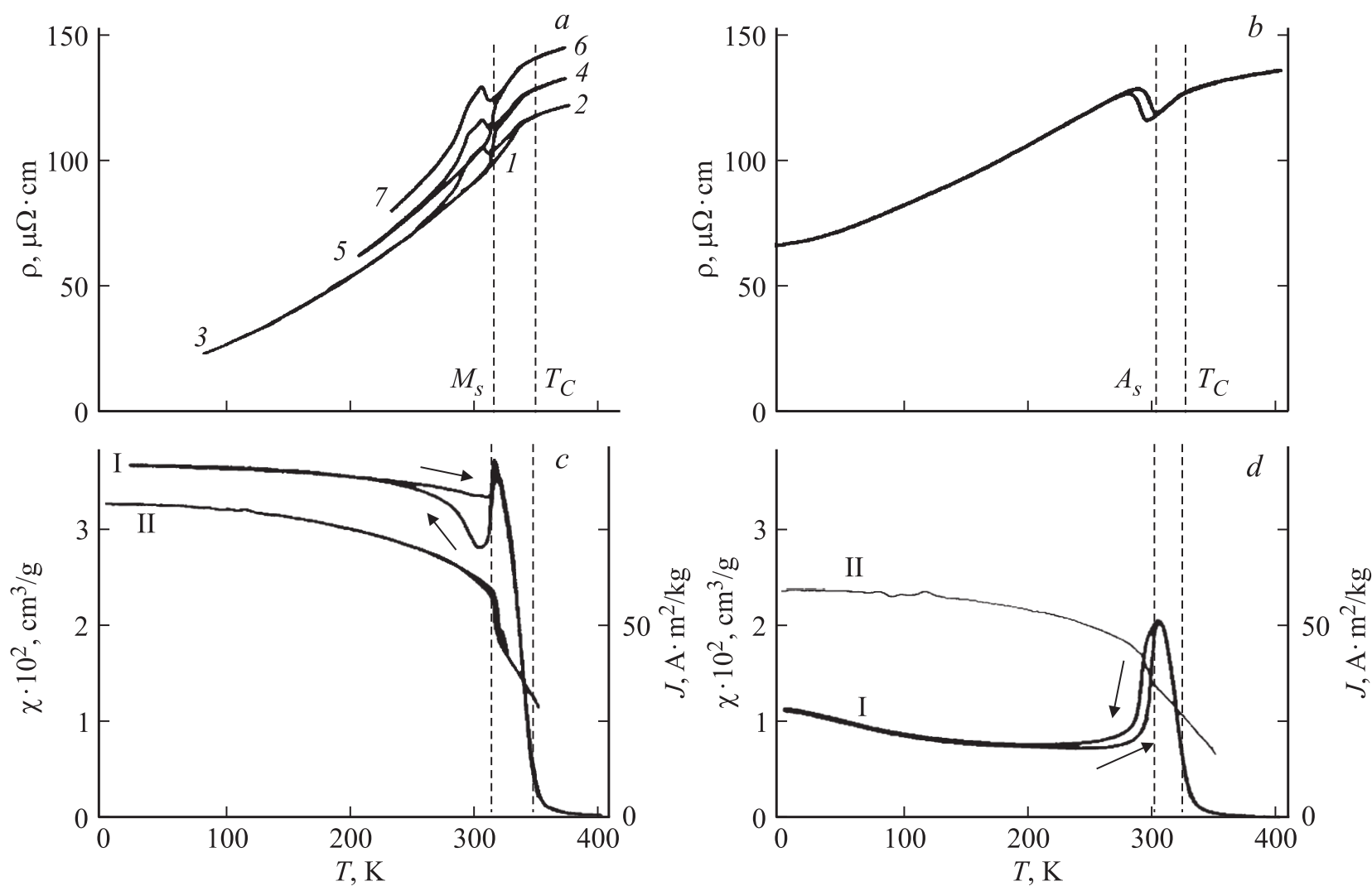

Рис. 1. Температурные зависимости электросопротивления $\rho(T)$, восприимчивости $\chi(T)$ (I) и намагниченности $J(H)$ (II) исходного литого $(a, c)$ и быстрозакаленного $(b, d)$ сплавов; намагниченность $J$ измерялась при $H=4 \mathrm{MA} / \mathrm{m}$, а восприимчивость $\chi(T)$ при $H=79.6 \mathrm{kA} / \mathrm{m}$. Для $\rho(T)$ литого сплава цифрами $1-7$ обозначена последовательность циклов измерений.

ратур между кривыми $\rho(T)$, полученными при охлаждении и нагреве, наблюдался гистерезис, практически полностью воспроизводимый при многократных циклах нагрев-охлаждение в образце (рис. 1,b). При этом

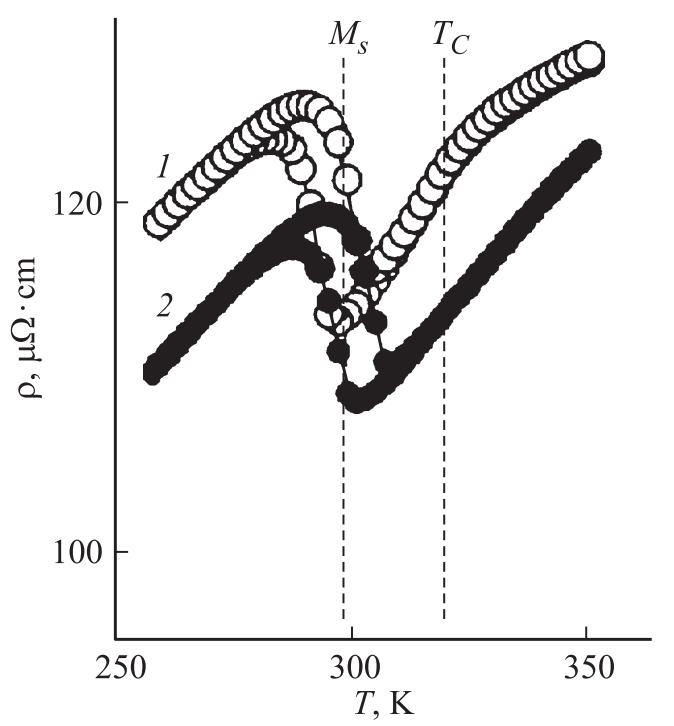

Рис. 2. Электросопротивление $\rho(T)$ БЗР-сплава $\mathrm{Ni}_{54} \mathrm{Mn}_{21} \mathrm{Ga}_{25}$ в нулевом магнитном поле $(1)$ и в поле $H=7.17 \mathrm{MA} / \mathrm{m}(2)$ в зависимости от температуры. сопротивление в мартенситной фазе (на выходе из скачка кривой $\rho(T)$ при $T<M_{f}$ или $\left.A_{s}\right)$ всегда больше сопротивления в аустенитной фазе (при температурах несколько более высоких, чем $M_{s}$ или $A_{f}$ ).

В исходном литом сплаве гистерезис кривых $\rho(T)$ имел более сложный вид, а температурный интервал, где он наблюдался, значительно больше, чем в быстрозакаленном сплаве (рис. $1, a$ ). Как видно из рис. 1, при понижении температуры литого сплава в точке ТМП $M_{s}$ увеличение сопротивления также происходило практически скачком, а затем кривая $\rho(T)$, снижаясь, испытывала два перегиба, которые могут быть интерпретированы как начало и конец второго мартенситмартенситного превращения. При нагреве с ростом температуры сопротивление $\rho$ увеличивалось, но при фазовом переходе из мартенситной в аустенитную фазу $\rho(T)$ исходного сплава (в отличие от БЗР) не уменьшалось, а также практически скачком (в узком интервале температур) возрастало, причем величина скачка $\rho(T)$ в интервале $M_{s}-M_{f}$ при понижении температуры меньше, чем при ее увеличении в интервале $A_{s}-A_{f}$, а положение скачков кривой $\rho(T)$ на оси температур в двух указанных случаях не совпадало, собственно определяя гистерезис. Это приводило к тому, что каждый цикл охлаждение-нагрев сопровождался необратимым возрастанием величины электросопротивления образца 
Таблица 2. Критические температуры начала и конца прямого и обратного ТМП литого и БЗР-сплава $\mathrm{Ni}_{54} \mathrm{Mn}_{21} \mathrm{Ga}_{25}$ в зависимости от величины магнитного поля $H$

\begin{tabular}{l|c|c|c|c|c}
\hline \multicolumn{1}{c|}{ Вид сплава } & $M_{s}, \mathrm{~K}$ & $M_{f}, \mathrm{~K}$ & $A_{s}, \mathrm{~K}$ & $A_{f}, \mathrm{~K}$ & $T_{C}, \mathrm{~K}$ \\
\hline Литой, $H \approx 0$ & 315 & 280 & 315 & 335 & 356 \\
Б3Р, $H \approx 0$ & 294 & 286 & 290 & 302 & 329 \\
Б3Р, $H \approx 7.17 \mathrm{MA} / \mathrm{m}$ & 298 & 290 & 298 & 306 & -
\end{tabular}

исходного сплава (рис. 1,a). Такое аномальное поведение $\rho(T)$ литого сплава $\mathrm{Ni}_{54} \mathrm{Mn}_{21} \mathrm{Ga}_{25}$ можно объяснить, по-видимому, только прогрессирующим механическим разрушением образца, обусловленным появлением в нем нарушений сплошности (микротрещин) в результате последовательных прямых и обратных ТМП, что было подтверждено при изучении поверхности образцов после измерений $\rho(T)$.

По полученным данным измерения $\rho(T)$ были определены критические температуры ТМП, интервалы между ними и гистерезис ТМП (табл. 2,3). Обращает на себя внимание, что в сильном магнитном поле напряженностью $H=7.17 \mathrm{MA} / \mathrm{m}$ данные температуры увеличились на 4-8 К по сравнению с температурами исходного БЗРсплава (рис. 2).

\section{4. Магнитные свойства сплавов}

Результаты измерений магнитной восприимчивости $\chi$, намагниченности $J$, а также удельного электросопротивления $\rho$ в магнитном поле приведены на рис. $1, c, d$ и 2. Видно, что в БЗР-сплаве величины намагниченности $J(H)$ при $H=4 \mathrm{MA} / \mathrm{m}$ и соответственно спонтанного момента, измеренные при $T=2 \mathrm{~K}$, уменьшились практически в 1.5 раза (рис. $1, d$ ). В области низких температур низкополевая $(H<80 \mathrm{kA} / \mathrm{m})$ магнитная восприимчивость снизилась примерно в 3 раза. Отмеченные изменения магнитных свойств свидетельствуют о появлении в БЗР-сплаве $\mathrm{Ni}_{54} \mathrm{Mn}_{21} \mathrm{Ga}_{25}$ конкурирующих ферро- и антиферромагнитных взаимодействий.

Вследствие некоторого атомного разупорядочения БЗР-сплава $\mathrm{Ni}_{54} \mathrm{Mn}_{21} \mathrm{Ga}_{25}$ поведение магнитных характеристик существенно различалось также в окрестностях температур магнитного и структурного превращений. Из сравнения рис. $1, c$ и $d$ видно, что в БЗР сплаве радикально изменился вид гистерезиса кривых $\chi(T)$, измеренных при охлаждении и нагреве образцов. При этом температурный интервал, в котором наблюдается гистерезис $\chi(T)$, уменьшился, а температуры ТМП $M_{s}$, $A_{s}, A_{f}$ несколько снизились, тогда как температура $M_{f}$, напротив, возросла.

Согласно [14], уменьшение значения температуры Кюри, установленное в БЗР-сплаве $\mathrm{Ni}_{54} \mathrm{Mn}_{21} \mathrm{Ga}_{25}$ (табл. 2), может быть обусловлено появлением в ближайшем окружении основного магнитоактивного атома $\mathrm{Mn}$ немагнитных атомов Ga. Обнаруженное при этом практическое отсутствие изменения величины $\mu_{\mathrm{eff}}$ (4.38 и $4.36 \mu_{\mathrm{B}} /$ f.u., где $\mu_{\mathrm{B}}-$ магнетон Бора) в условиях резкого увеличения отношения $\mu_{\mathrm{eff}} / \mu_{s}$ (где $\mu_{s}-$ спонтанный магнитный момент) при частичном атомном и структурном разупорядочении сплава свидетельствует об определяющем влиянии конкурирующих ферро- и антиферромагнитных взаимодействий как на величину, так и на процесс намагничивания в сильных магнитных полях.

Сравнение температурных зависимостей $\rho(T)$, измеренных в нулевом магнитном поле и при $H=7.17 \mathrm{MA} / \mathrm{m}$, убедительно демонстрирует, что под действием приложенного магнитного поля температуры ТМП возрастают: $M_{s}, M_{f}, A_{f}-$ на $4 \mathrm{~K}$, а $A_{s}$ - на $8 \mathrm{~K}$ (ср. кривые на рис. 2).

\section{5. Механическое поведение сплавов}

Ленточные образцы БЗР-сплава толщиной $t=40 \mu \mathrm{m}$ и длиной 10-15 mm деформировались на цилиндрических оправках диаметром $D=2 \mathrm{~mm}$ изгибом на $180^{\circ}$ (на величину изгиба $\gamma=100 \% \cdot \mathrm{t} / \mathrm{D}=2 \%$ ) при комнатной температуре, а затем проводился нагрев для реализации ЭПФ (рис. 3). Даже 3000 таких циклов деформация-нагрев-охлаждение не привели к разрушению образцов, а степень возвращения их $C$-образной формы в прямолинейную была близка к 100\%. Еще большей термомеханической циклостойкостью обладали образцы лент БЗР-сплава после отжига при $1073 \mathrm{~K}$. Подобные эксперименты на образцах исходного литого сплава выполнить не удалось из-за их хрупкого разрушения уже при изгибе на $0.5-1.0^{\circ}$.

Таблица 3. Температурные интервалы при реализации прямого и обратного ТМП литого и Б3Р-сплава $\mathrm{Ni}_{54} \mathrm{Mn}_{21} \mathrm{Ga}_{25}$ в зависимости от величины магнитного поля $H$

\begin{tabular}{l|c|c|c|c|c|c|c}
\hline \multicolumn{1}{c|}{ Вид сплава } & $M_{s}-M_{f}, \mathrm{~K}$ & $A_{f}-A_{s}, \mathrm{~K}$ & $M_{s}-A_{s}, \mathrm{~K}$ & $A_{f}-M_{f}, \mathrm{~K}$ & $A_{s}-M_{f}, \mathrm{~K}$ & $A_{f}-M_{s}, \mathrm{~K}$ & $\Delta T,{ }^{*} \mathrm{~K}$ \\
\hline Литой, $H \approx 0$ & 35 & 20 & 0 & 55 & 35 & 20 & 27 \\
БЗР, $H \approx 0$ & 8 & 12 & 4 & 16 & 4 & 8 \\
БЗР, $H \approx 7.17 \mathrm{MA} / \mathrm{m}$ & 8 & 8 & 0 & 16 & 8 & 8 & 8
\end{tabular}

${ }^{*} \Delta T=\left\{\left(A_{f}+A_{s}\right)-\left(M_{s}+M_{f}\right)\right\} / 2$. 
$a$

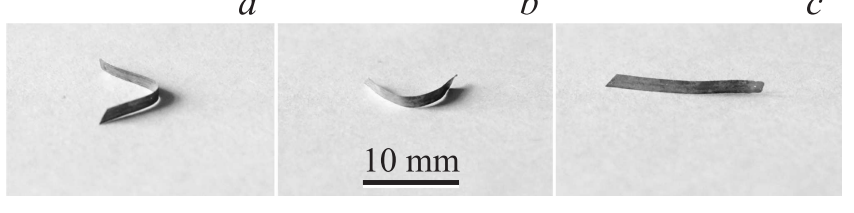

Pис. 3. Фотографии БЗР-ленты при термомеханических испытаниях для реализации ЭПФ: придание прямолинейной ленте изгибом С-образной формы при комнатной температуре $(a)$, частичное самопроизвольное распрямление при нагреве в межкритическом интервале температур $(b)$, полное выпрямление образца при нагреве до завершения ТМП (c).

\section{6. Фазовые и структурные превращения в сплавах}

Проведенные структурные исследования показали следующее. Согласно данным SEM, средний размер практически равноосных зерен в БЗР-сплаве $\mathrm{Ni}_{54} \mathrm{Mn}_{21} \mathrm{Ga}_{25}$ составлял несколько микрометров (рис. 4,a). Это в 500-1000 раз меньше размера зерен в исходном литом сплаве, в котором также весьма велик их разброс по размерам, морфологии и химическому составу вследствие ликвации в процессе затвердевания, приводящей к его флуктуациям от номинального на $0.5-1.0$ at $\%$.

ТЕМ электролитически утоненных фольг была проведена методом in situ в гониометрических держателях, позволяющих выполнять нагрев или охлаждение в колонне микроскопа. Установлено, что высокотемпературная аустенитная фаза в сплаве имела атомноупорядоченную кристаллическую структуру типа $L 2_{1}$, о чем прямо свидетельствовали регистрируемые на микроэлектронограммах сверхструктурные рефлексы типа 111 и 002 (рис. 5,c). При этом на электронномикроскопических изображениях аустенита при комнатной температуре и при нагреве in situ наблюдался твидовый дифракционный контраст деформационного происхождения. Он образован характерными элементами контраста размером от 1 до $10 \mathrm{~nm}$ в зависимости от наклона образцов, которые были ориентированы вдоль следов пересечения плоскостей типа $\{110\} L 2_{1}$ с поверхностью фольги (рис. 5,6). Интенсивность твидового контраста зависела от действующего отражения (cp. рис. $5, a, b)$ и по визуальной оценке несколько убывала при нагреве. На контурах экстинкции данный контраст имел максимальную интенсивность.
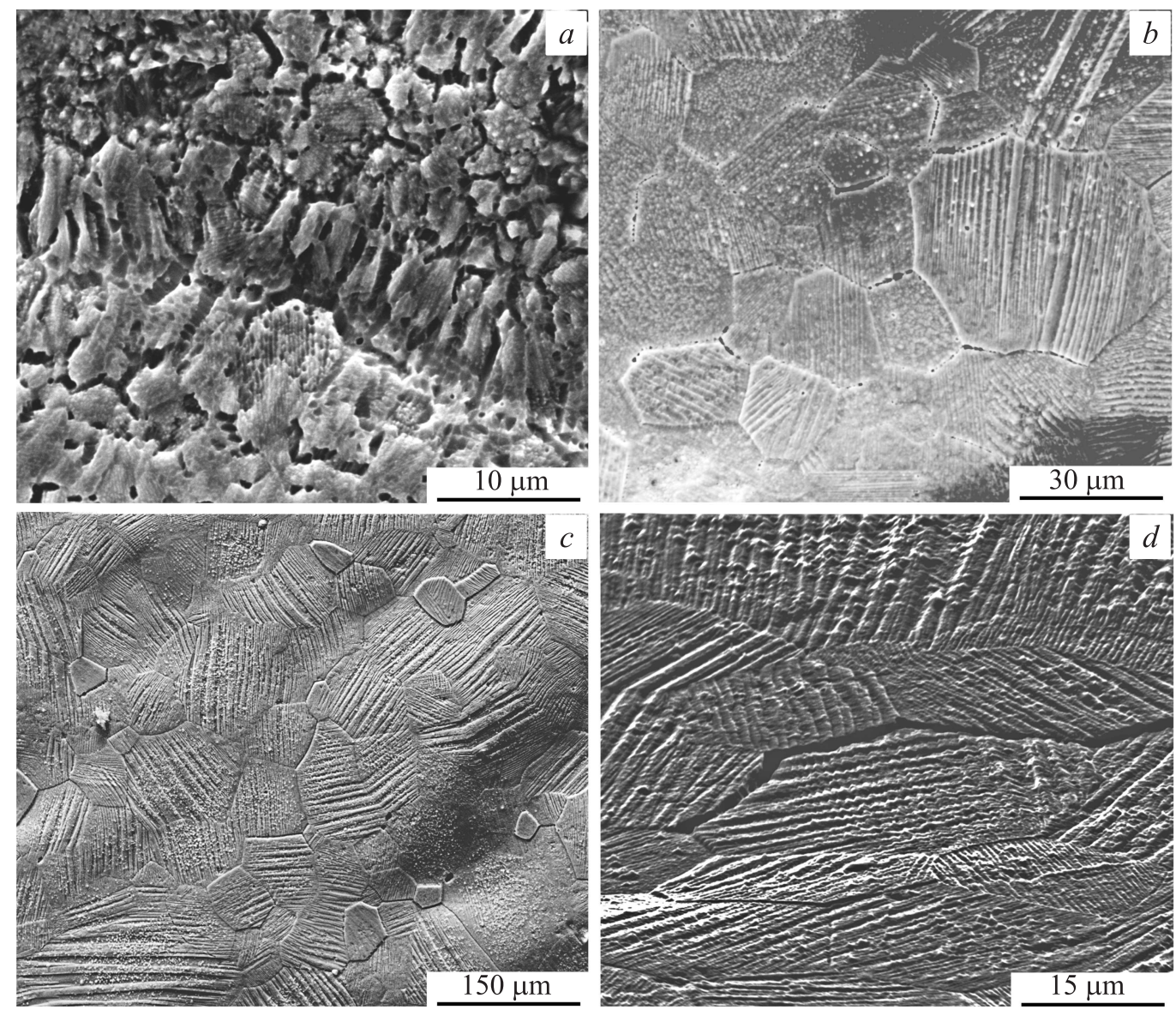

Рис. 4. SEM-изображения БЗР-сплава $\mathrm{Ni}_{54} \mathrm{Mn}_{21} \mathrm{Ga}_{25}$ в исходном состоянии $(a)$, после отжига при $1073 \mathrm{~K}$ в течение $5 \mathrm{~h}(b)$ и после отжига при $1073 \mathrm{~K}$ в течение $72 \mathrm{~h}(c, d)$. 


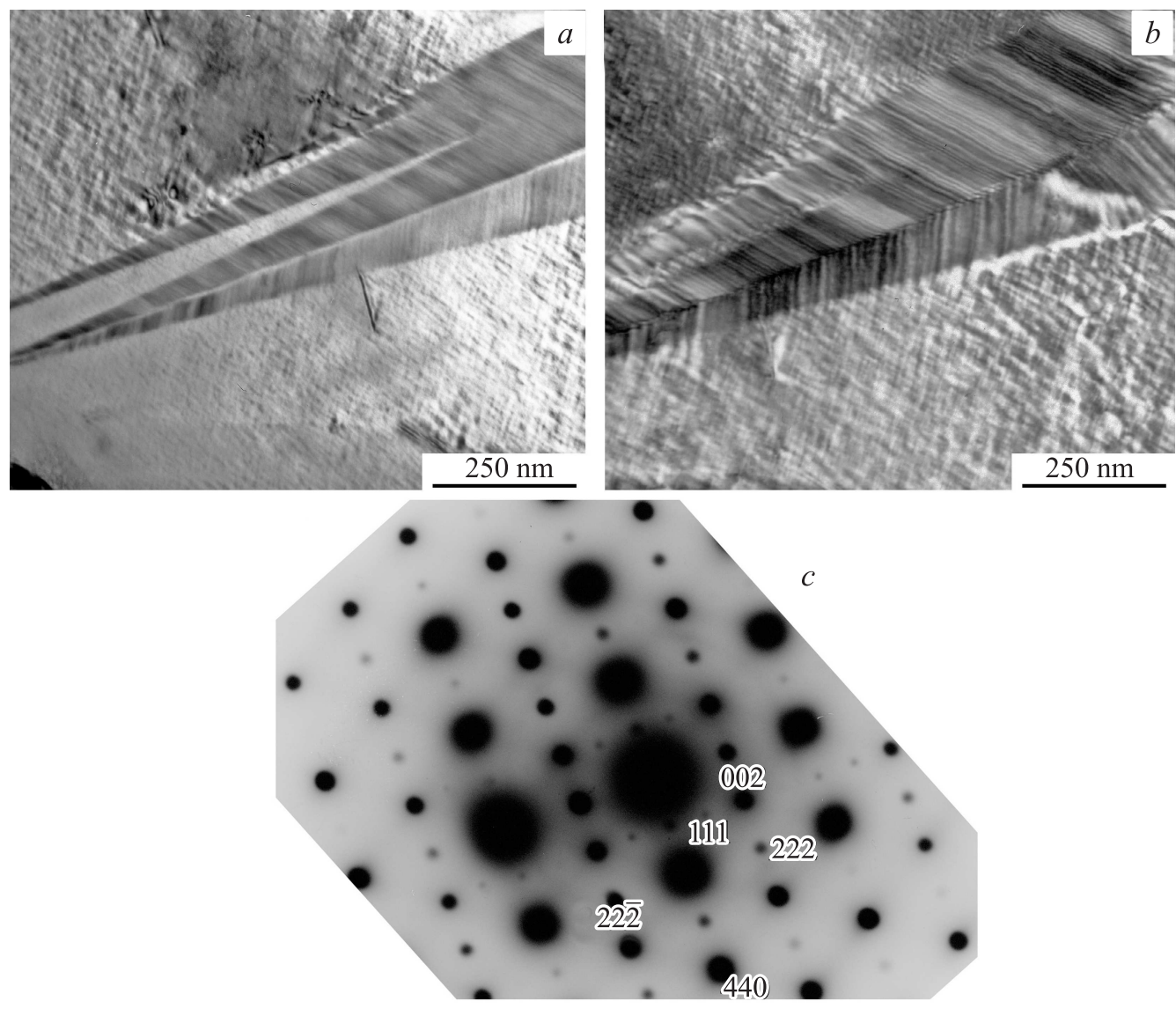

Рис. 5. ТЕМ-изображения $(a, b)$ и соответствующая микроэлектронограмма $(c)$ литого сплава.
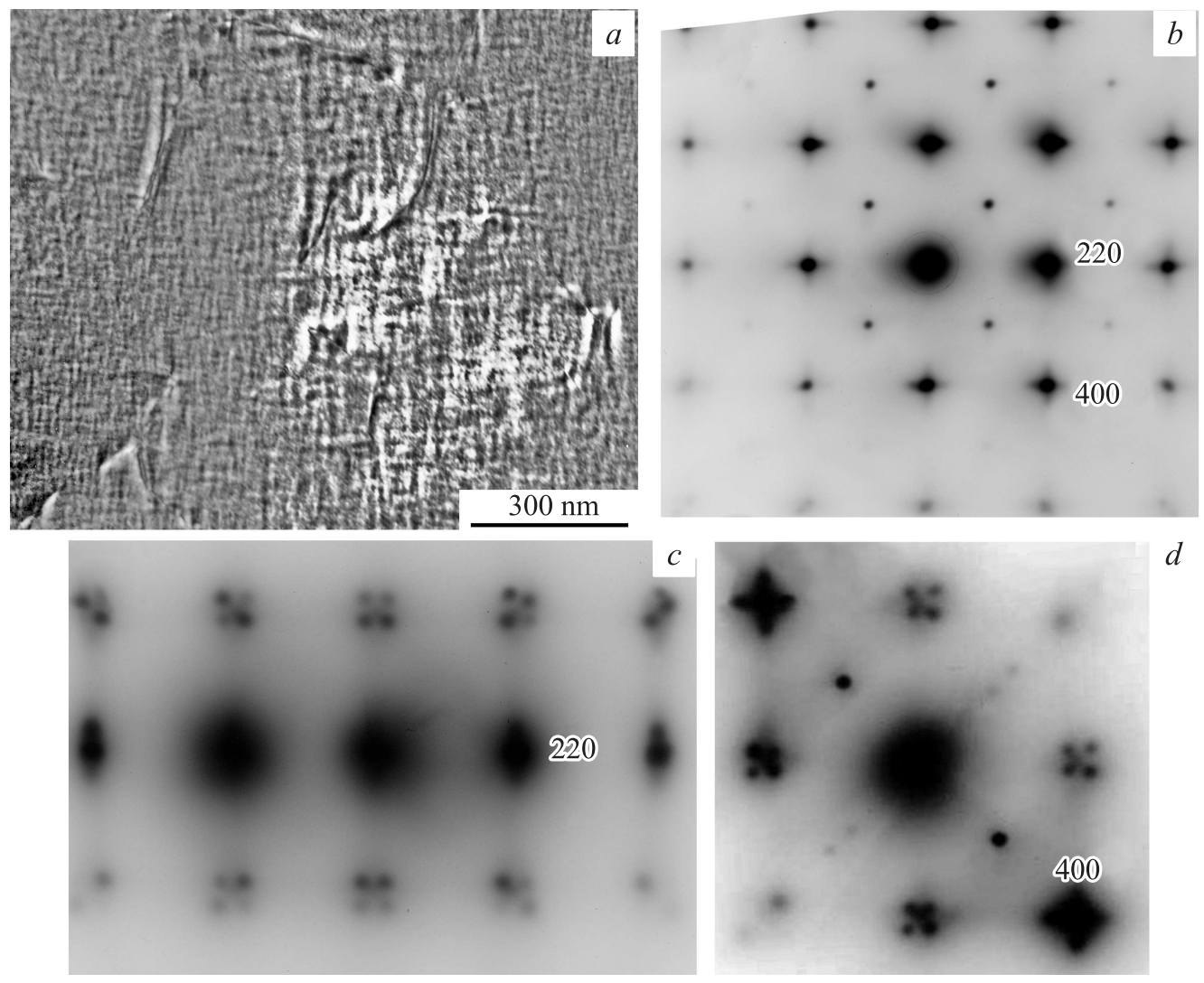

Рис. 6. ТЕМ-изображение $(a)$ и соответствующие микроэлектронограммы $(b-d) L 2_{1}$-аустенита БЗР-сплава. 

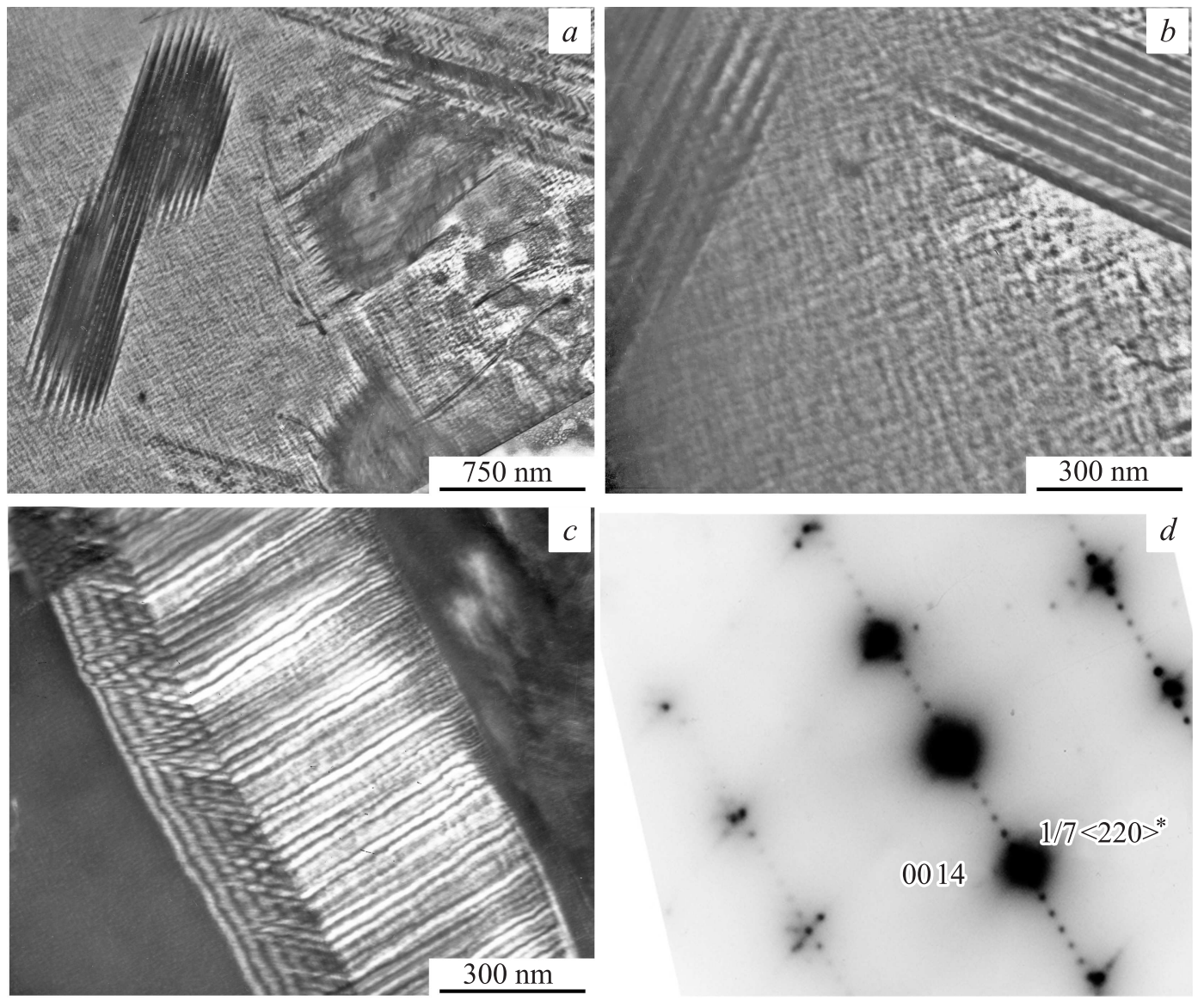

Рис. 7. ТЕМ-изображения $(a-c)$ и соответствующая микроэлектронограмма $(d)$ длиннопериодного мартенсита литого сплава при комнатной температуре $(a, b)$ и $170 \mathrm{~K}(c, d)$.

Характерной чертой микроэлектронограмм $L 2_{1}$-аустенита являлось присутствие на них протяженных эффектов диффузного рассеяния в виде нерадиальных тяжей, которые, как показал анализ, представляли собой следы пересечения сферы Эвальда с диффузными слоями, расположенными по плоскостям $\{111\}^{*}$ обратной решетки $L 2_{1}$ [1-3]. Наиболее интенсивные нерадиальные тяжи по направлениям $\langle 110\rangle^{*}$ наблюдались вблизи структурных рефлексов (рис. $6, b-d$ ). Важная отличительная особенность данного диффузного рассеяния электронов наличие усилений интенсивности, расположенных на тяжах по направлениям $\langle 110\rangle^{*}$ в положениях $1 / 6\langle 220\rangle^{*}$ (или $1 / 3\langle 110\rangle^{*}$ ) (рис. 6). Они более четко визуализировались при температурах ниже $T_{C}$, но наблюдались и в парамагнитном аустените. Эти данные хорошо согласуются с нейтронными [6,7]. На рис. 6 приведены микроэлектронограммы с осью зоны отражающих плоскостей типа $[001] L 2_{1}$ в точном положении $(b)$ и после наклона фольги на несколько градусов вращением вокруг оси $[110](c)$ или оси [100] $(d)$. В этих трех случаях наряду с нерадиальными диффузными тяжами, лежащими в плоскости электронограммы, и усилениями на них в положениях типа $1 / 3\langle 110\rangle^{*}$ на двух последних микродифрактограммах видны „четверки“ или „двойки“ развернутых под углом $45^{\circ}$ к направлению типа $\langle 110\rangle^{*}$ экстрарефлексов, происхождение которых связано с ,проколами“ сферы отражения Эвальда интенсивными тяжами по $\langle 110\rangle^{*}$, не принадлежащими данному сечению обратной решетки. Полученные дифракционные результаты достаточно полно описывают нанодоменное предмартенситное состояние в исходной средней решетке $L 2_{1}$, смещения атомов в которой описываются модуляцией утроенной волны поперечных смещений $3 \cdot(110)[\overline{1} 10]$ [1-4], и хорошо коррелируют с нейтронными измерениями мягкомодового поведения сплавов $\mathrm{Ni}_{50} \mathrm{Mn}_{25} \mathrm{Ga}_{25}[6,7]$.

При комнатной температуре литой сплав, так же как и БЗР-сплав, находился в двухфазном аустенитномартенситном состоянии (рис. $5, a, b$ и $7, a, b$ ). Пластинчатые и остроугольные кристаллы мартенсита, как правило, располагались под углом к поверхности фольги и имели тонкодвойникованную субструктуру параллельно одному из семейств плоскостей типа $\{110\} L 2_{1}$. Габитус кристаллов и микродвойников также близок $\{110\} L 2_{1}$. На микроэлектронограммах вдоль диффузных тяжей присутствовали экстрарефлексы в положениях $1 / 5\langle 220\rangle^{*}$, эквидистантно расположенные по направлениям, параллельным $\langle 110\rangle^{*} L 2_{1}$. Они, как известно, обусловлены формированием модулированной структуры мартенсита $10 M$. 

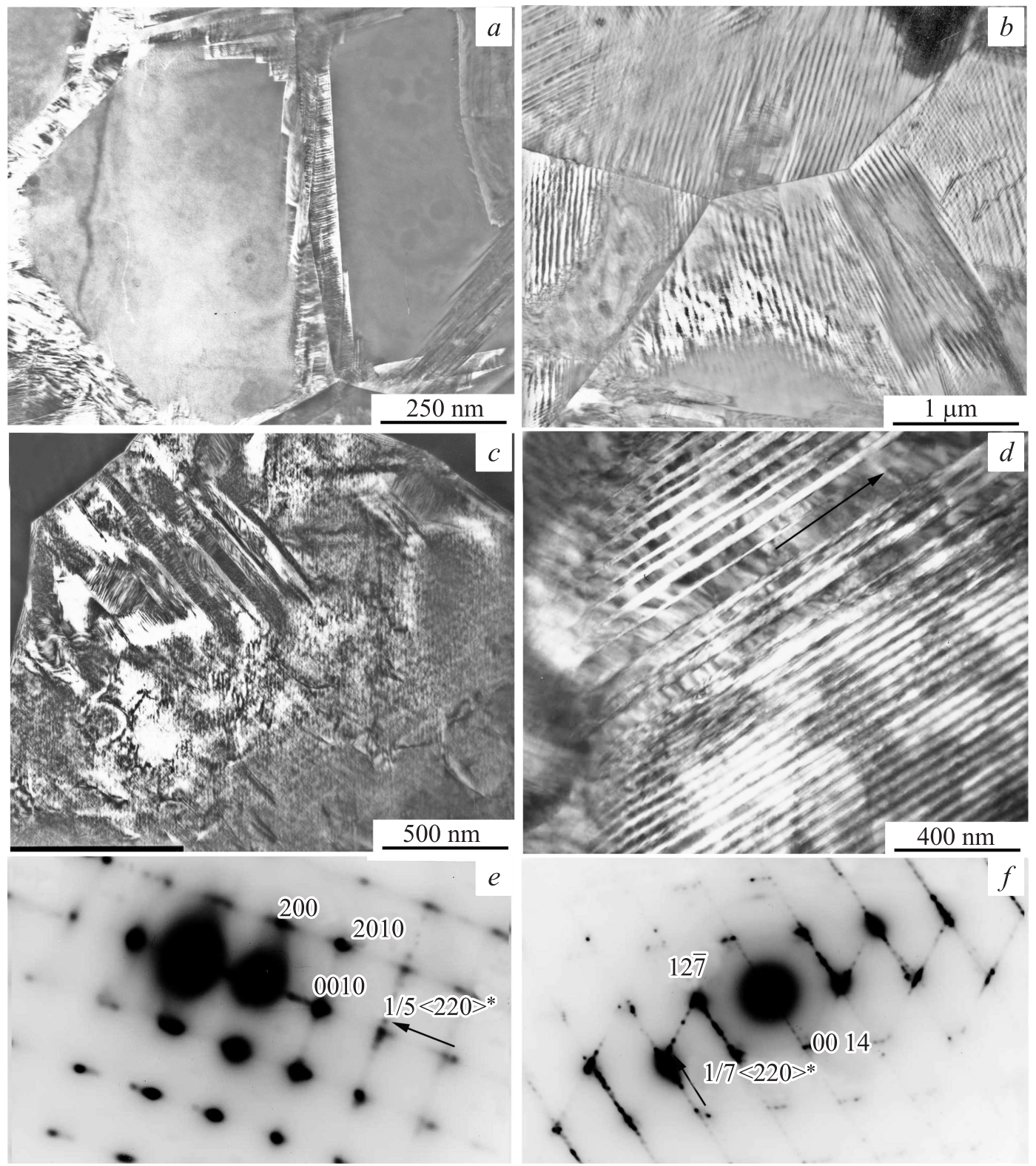

Рис. 8. ТЕМ-изображения и соответствующие электронограммы БЗР-сплава при комнатной температуре (a,c,e) и при $170 \mathrm{~K}(b, d, f)$.

Охлаждение литого сплава ниже комнатной температуры приводило к быстрому завершению ТМП (табл. 2,3). При этом оказалось, что области остаточного аустенита, как и кристаллы мартенсита $10 M$, испытывали ТМП в тонкопластинчатый мартенсит $14 M$ (рис. 7,c). Их габитус также близок к $\{110\} L 2_{1}$. Микродифракционные картины, полученные от тонкопластинчатого мартенсита $14 M$ (одна из них приведена на рис. $7, d)$, содержали ряды экстрарефлексов уже типа $1 / 7\langle 220\rangle^{*}$ вдоль определенных направлений (бывших $\left.\langle 110\rangle^{*} L 2_{1}\right)$.

В БЗР-сплаве, полученном спиннингованием, прямое ТМП происходило в интервале температур 294-286 К (табл. 2,3). Поэтому уже при комнатной температуре удалось установить некоторые его особенности в мелкозернистом БЗР-сплаве по сравнению с исходным литым крупнозернистым сплавом-прототипом (рис. 4-8). Прежде всего отчетливо выявился зернограничный механизм ТМП $L 2_{1} \rightarrow 10 M$, при котором границы зерен „декорировались“ мартенситными кристаллами и, кроме того, наблюдались отходящие от них в глубь зерен отдельные мартенситные пластины и их пакеты (рис. 8,a,c,e). При охлаждении in situ ТМП завершалось во всех зернах с образованием попарно двойникованного мартенсита $14 M$ однопакетной морфологии (рис. $8, b, d, f$ ). Таким образом, первоначально двухфазный при комнатной температуре сплав $L 2_{1}+10 M$ испытал двухступенчатое аустенит-мартенсит-мартенситное 
превращение $L 2_{1} \rightarrow 10 M \rightarrow 14 M$, поскольку его микродифракционные картины теперь содержат дополнительные экстрарефлексы типа $1 / 7(220)^{*}$ (рис. 8,f). Однако по-прежнему в сплаве присутствовали отдельные более широкие недвойникованные пластинчатые кристаллы тетрагонального немодулированного мартенсита NM $(c / a \sim 1.2)$, отмеченного стрелкой на рисунке, которые, по-видимому, могут сохраняться при охлаждении (рис. 8, $d$ ).

SEM методом дифракции обратно рассеянных электронов (EBSD) и рентгеноструктурный анализ в целом подтвердили особенности ТМП в литых и БЗР-сплавах и их последовательность по схеме $L 2_{1} \leftrightarrow 10 M \leftrightarrow 14 M$ (рис. 9,10). В отличие от случая БЗР-сплава особен-
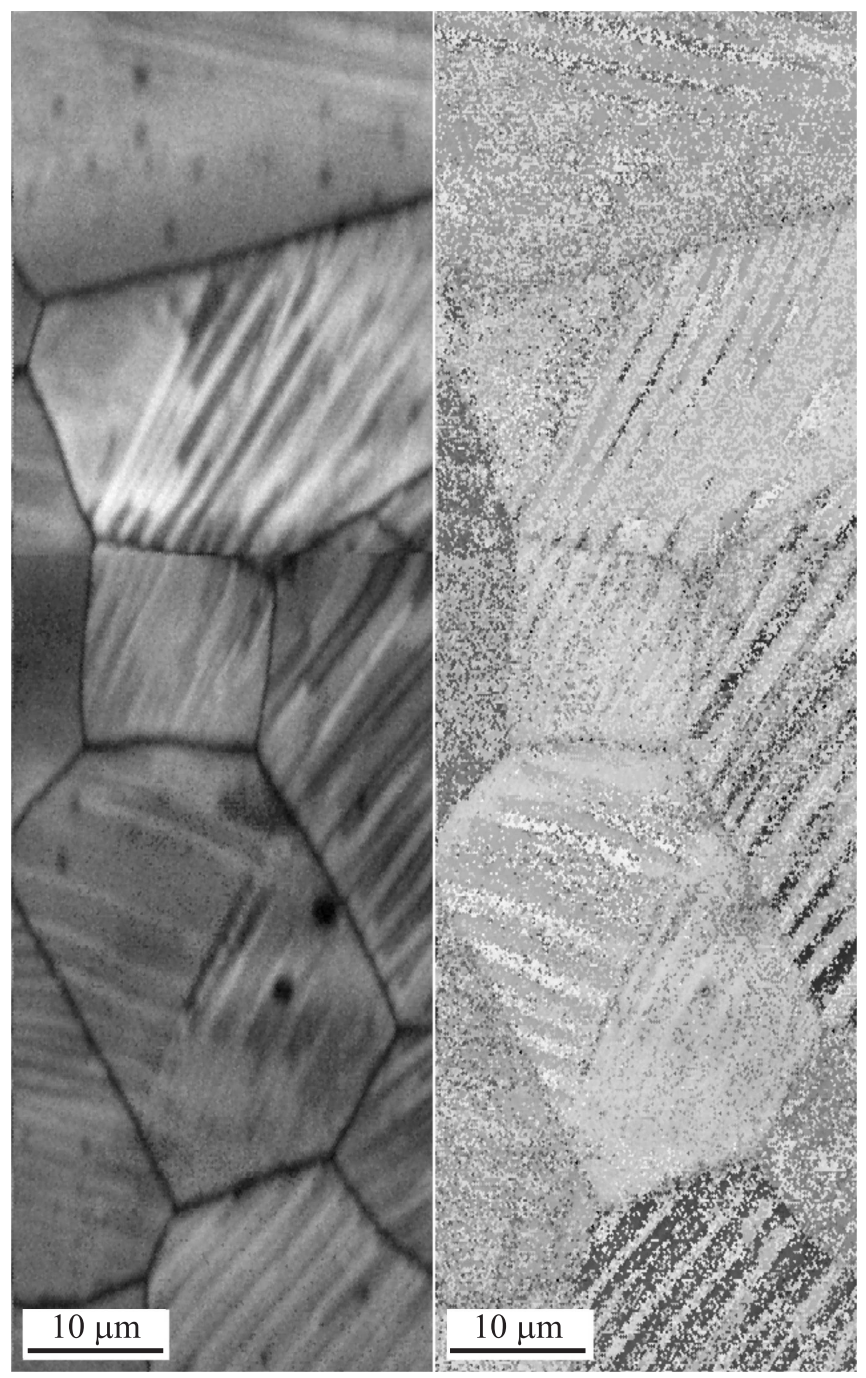

Рис. 9. Карты распределения двойникованной зеренной микроструктуры БЗР-сплава после отжига при температуре $1073 \mathrm{~K}$ в течение $72 \mathrm{~h}$ по их линейным размерам и кристаллографическим ориентациям, полученные методом SEM (EBSD). Дискретный контраст микродвойниковой структуры (правая часть рисунка) обусловлен шагом сканирования, превышающим линейные размеры тонких вторичных нанодвойников.

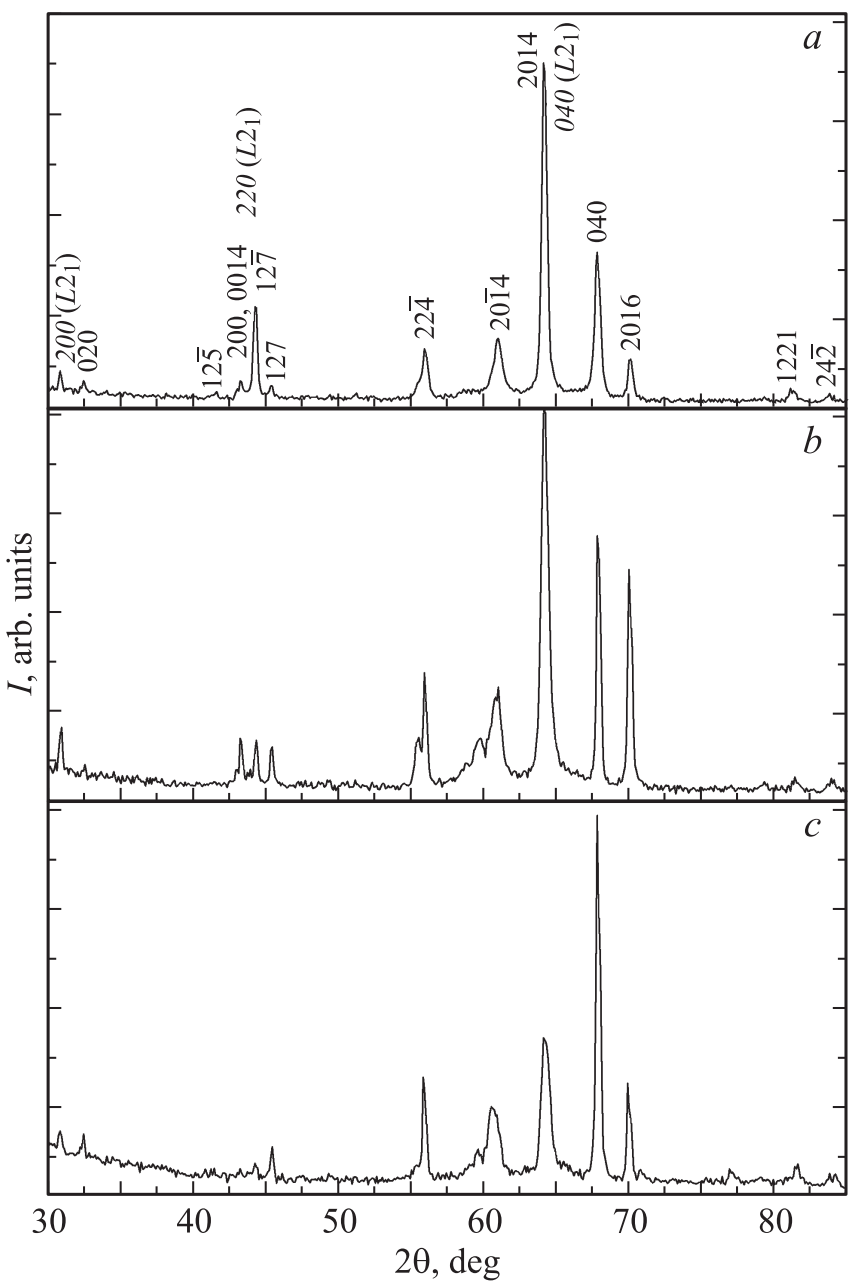

Рис. 10. Рентгенограммы сплава $\mathrm{Ni}_{54} \mathrm{Mn}_{21} \mathrm{Ga}_{25}$ с сильной кристаллографической кубической текстурой остаточного $L 2_{1}$-аустенита (курсив), наследуемой $14 M$-мартенситом. $a-$ исходное БЗР-состояние, $b, c-$ БЗР-сплав после отжига при $1073 \mathrm{~K}$ в течение $5 \mathrm{~h}$ и при $1073 \mathrm{~K}$ в течение $72 \mathrm{~h}$ соответственно.

ностью исходного литого сплава являлась неполная обратимость данной последовательности при нагреве: $14 M \leftrightarrow L 2_{1}$. Вместе с тем микрозеренная структура БЗР-сплава имела сильную кубическую кристаллографическую текстуру, что отчетливо видно как из анализа соотношения интенсивностей брэгговских отражений аустенита и мартенсита БЗР-сплава (рис. 10), так и из его EBSD-изображений (рис. 9).

Отжиг БЗР-сплава при $1073 \mathrm{~K}$ (в течение 5 и $72 \mathrm{~h}$ ) привел не только к некоторому возрастанию размеров зерен $L 2_{1}$-аустенита, но и к их более равновесно ограненной форме (рис. $4, b-d$ ) и как следствие к повышению пластичности тонких лент при деформации на изгиб и к повышению критических температур ТМП до значений несколько выше комнатной температуры. Однопакетный характер морфологии мартенсита в целом в БЗР-сплаве сохранился. 


\section{7. Заключение}

Таким образом, в результате проведенных исследований было обнаружено, что сверхбыстрая закалка сплава $\mathrm{Ni}_{54} \mathrm{Mn}_{21} \mathrm{Ga}_{25}$, вызывающая существенное (на три порядка) измельчение зеренной микроструктуры, несмотря на некоторое уменьшение степени атомного и магнитного порядков, приводит к значительному возрастанию физико-механической устойчивости образцов, их деформационной термоциклической прочности и пластичности. При этом в полной мере сохраняются предмартенситные явления, магнитный фазовый переход и высокообратимые термоупругие мартенситные превращения, а также связанные с ними эффекты памяти формы. Температурный гистерезис физических свойств и термомагнитоупругого мартенситного превращения, наблюдаемый в окрестности критических точек, в быстрозакаленном мелкозернистом сплаве значительно уменьшился, а в магнитном поле $H=7.17 \mathrm{MA} / \mathrm{m}$ сместился на 4-8 K в область более высоких температур.

Термоупругие мартенситные превращения в исходном литом сплаве происходили в большем интервале температур и не являлись полностью структурно-обратимыми (при нагреве мартенсит 10M не был обнаружен). Следствием структурно-механической неустойчивости литого крупнозернистого сплава с присущей ему химической ликвацией, усугубляемой высокой склонностью к хрупкому разрушению, стали необратимые изменения тех свойств, которые к ним чувствительны. Эти необратимые изменения свойств практически отсутствовали в быстрозакаленном мелкозернистом и химически более однородном сплаве.

Частичное атомное разупорядочение исходной структуры $L 2_{1}$ в быстрозакаленном сплаве $\mathrm{Ni}_{54} \mathrm{Mn}_{21} \mathrm{Ga}_{25}$ привело к появлению конкурирующих ферро- и антиферромагнитных взаимодействий. При температурах ниже $T_{C}$ это сказывается на величине и температурной зависимости магнитных характеристик быстрозакаленного сплава. В то же время степень локализации магнитного момента и другие электронные характеристики в результате разупорядочения рассматриваемого коллективизированного магнетика практически не изменились. Это свидетельствует об устойчивости электронной зонной структуры вблизи уровня Ферми для сплавов, полученных двумя рассматриваемыми в настоящей работе способами.

\section{Список литературы}

[1] В.В. Кондратьев, В.Г. Пушин. ФММ 60, 4, 629 (1985).

[2] В.Г. Пушин, В.В. Кондратьев. ФММ 78, 5, 40 (1994).

[3] V.G. Pushin. Phys. Met. Metallogr. 90, Suppl. 1, 68 (2000).

[4] А.Н. Васильев, В.Д. Бучельников, Т. Тагаки, В.В. Ховайло, Э.И. Эстрин. УФН 173, 6, 577 (2003).

[5] В.Н. Хачин, С.А. Муслов, В.Г. Пушин, Ю.И. Чумляков. ДАН СССР 295, 3, 606 (1987).
[6] A. Zheludev, S.M. Shapiro, P. Wochner, L.E. Tanner. Phys. Rev. B 54, 21, 15045 (1996).

[7] L. Manos̃a, A. Planes, J. Zarestky, T. Lograsso, D.L. Schlagel, C. Stassis. Phys. Rev. B 64, 024305 (2001).

[8] J. Worgull, E. Petti, J. Trivisonno. Phys. Rev. B 54, 22, 15695 (1996)

[9] P.J. Webster, K.R.A. Ziebeck, S.L. Town, M.S. Peak. Phil. Mag. B 49, 3, 295 (1984).

[10] V.A. Chernenko, C. Segui, E. Cesari, J. Pons, V.V. Kokorin. J. Phys. IV (France) 7, C5-137 (1997).

[11] J. Pons, V.A. Chernenko, R. SantaMarta, E. Cesari. Acta Mater. 48, 3027 (2000).

[12] N. Lanska, O. Soderberg, A. Sozinov, Y. Ge, K. Ullakko, V.K. Lindroos. J. Appl. Phys. 95, 12, 8074 (2004).

[13] В.В. Кокорин, В.В. Мартынов. ФММ 72, 3, 101 (1991).

[14] M. Kreissl, K.-U. Neumann, T. Tephens, K.R.A. Ziebeck. J. Phys.: Condens. Matter 15, 3831 (2003).

[15] Н.И. Коуров, А.В. Королев, В.Г. Пушин, В.В. Коледов, В.Г. Шавров, В.В. Ховайло. ФММ 99, 4, 38 (2005).

[16] Н.И. Коуров, В.Г. Пушин, А.В. Королев, В.А. Казанцев, Е.Б. Марченкова, А.Н. Уксусников. ФММ 103, 3, 280 (2007).

[17] Н.И. Коуров, В.В. Марченков, В.Г. Пушин, А.В. Королев, Е.Б. Марченкова, Н.W. Weber. ФТТ 50, 11, 2037 (2008).

[18] Н.И. Коуров, В.Г. Пушин, А.В. Королев, В.В. Марченков, Е.Б. Марченкова, В.А. Казанцев, H.W. Weber. ФТТ 53, 1, 89 (2011).

[19] В.Г. Пушин, Н.И. Коуров, А.В. Королев, Е.Б. Марченкова, Н.Н. Куранова, Е.С. Белослудцева. ФТТ 57, 1, 43 (2015).

[20] А.В. Королев, Н.И. Коуров, В.Г. Пушин. ФТТ 57, 2, 302 (2015).

[21] Z. Wang, M. Matsumoto, S.T. Pantelides, K. Oikawa, J. Qiu, T. Takagi, J. Tani. Mater. Sci. Forum 327-328, 489 (2000).

[22] С.В. Вонсовский. Магнетизм. Наука, М. (1971). 1032 с.

[23] Ф. Блатт. Физика электронов проводимости в твердых телах. Мир, М. (1971). 470 с. 